\title{
Pajarito nuevo la lleva. Teatro e memóriA estratégias de representacăo e claboracăo cênica da memória traumática infantil
}

\author{
María José Contreras \\ Pontifícia Universidade Católica do Chile \\ Milena Grass Kleiner \\ Pontifícia Universidade Católica de Chile \\ Nancy Nicholls \\ Universidade Acadêmica de Humanismo Cristão
}

\begin{abstract}
RESU M O
O presente artigo relata uma pesquisa cênica realizada a partir de testemunhos coletados entre aqueles que eram crianças na época do Golpe de Estado (Chile - 1973) e no período de protestos dos anos 1980. Os objetivos do projeto foram resgatar uma memória que não foi considerada oficialmente como parte do projeto de reconciliação e reconstrução nacional, e revisar suas possibilidades de tradução performática para promover, assim, a elaboração coletiva do trauma cultural em relação ao que a ditadura significou para o Chile..
\end{abstract}

\section{PALAVRAS - CHAVE}

Teatro. Memória. Infância.

\begin{abstract}
$\bigcirc$ projeto de pesquisa "Teatro e memória. Estratégias de representação e elaboração cênica da memória traumática infantil” ${ }^{1}$ teve uma gênese múltipla para onde confluíram interesses pessoais e institucionais, e também um certo espírito de época, pelo qual começaremos esta exposição.
\end{abstract}

\footnotetext{
${ }^{1} \mathrm{O}$ projeto foi realizado entre os meses de junho e agosto de 2008 e contou com a participação de María José Contreras (diretora), Nancy Nicholls (historiadora), Milena Grass (analista teatral), Ornella de la Vega (assistende de direção) e os atores e atrizes Macarena Béjares, Pablo Dubott, Simón Lobos, Álvaro Manríquez, Carolina Quito e Andrea Soto. O financiamento para sua realização veio dos concursos Cultura e Criação Artística (VRAID N 15/2008) da Pró-reitoria adjunta de Pesquisa e Doutorado da Pontifícia Universidade Católica do Chile e Laboratório Teatral 2008 da Escola de Teatro UC.
} 


\section{Alguns anteCEdentes}

Desde o ponto de vista teórico, podemos dizer que tanto a memória quanto os diversos sistemas metodológicos que se dedicam ao seu estudo presenciaram, nas últimas décadas, um notável crescimento. No ano de 1925, quando Maurice Halbwachs publicou Los cuadros sociales de la memoria, inaugurou-se um crescimento exponencial dos estudos dedicados ao assunto, e, ultimamente, sabemos que conhecidos teóricos ${ }^{2}$ têm dado suas contribuições neste campo a partir de diferentes perspectivas - histórica, sociológica, antropológica, semiótica, estética. Um dos eixos que orientavam este projeto teórico era tentar compreender um século cruel, o XX, em que o extermínio étnico massivo e reiterado levava a um questionamento da continuidade das tradições e da função da memória como aquilo que evitaria a repetição dos mesmos erros do passado.

Paralelamente a este desenvolvimento teórico, o Chile, devido à sua história recente, sofreu na própria carne, nas últimas décadas, uma discussão inflamada sobre a memória, em que as múltiplas redes de lembranças que coexistem procuram o seu espaço e disputam uma posição hegemônica. ${ }^{3} \mathrm{O}$ projeto do Acordo pós-ditatorial fez enormes esforços para obter a reconciliação nacional, reconciliação que seria a única forma viável de possibilitar a convivência entre torturados e torturadores, e evitar uma ruptura nacional que impediria o crescimento e a estabilidade econômica que o país herdou da ditadura e que todos os governos que a sucederam fomentaram. Assim, convivem no Chile diversas memórias, algumas legitimadas como história oficial; outras, ainda em processo de se legitimar; muitas, finalmente, que se deterioram e se perdem no silêncio.

Estes antecedentes sobre a preeminência da memória na reflexão geral e sobre a realidade chilena se somam, na origem desta pesquisa, a uma preocupação pela historiografia do século XX, campo repleto de perguntas inovadoras que conduziram a disciplina da história por caminhos totalmente inéditos e impensáveis desde o cenário positivista. Algumas das perguntas levantadas com relação ao objeto da história (o passado, os acontecimentos, o transcorrer da humanidade no tempo, certos espaços?) e também com relação à ordem discursiva que organiza a produção dos historiadores (com as contribuições do Roland Barthes ${ }^{4}$ referentes aos recursos metalinguísticos que constroem o efeito de realidade e a polêmica de $\mathrm{H}$. White ${ }^{5}$ em termos da existência de tropos literários subjacentes ao discurso histórico, que determinariam a forma com que o historiador entende e aborda os dados, elaborando uma narração tendenciosa em termos políticos) e finalmente com respeito às fontes (com uma preeminência do arquivo acima de qualquer outra forma de registro dos acontecimentos); algumas dessas perguntas, como se dizia, ecoavam, ao pensarmos nos problemas da prática teórica do

\footnotetext{
${ }^{2}$ Cf. NORA. Les lieux de mémoire; AUGÉ. Las formas del olvido; RICCEUR. La mémoire, l'histoire, l'oubli; TRAVERSO. El pasado, instrucciones de uso. Historia, memoria, política; HUYSSEN. En busca del futuro perdido. Cultura y memoria en tiempos de globalización; DEMARIA. Semiotica y memoria. Analisi del post-conflito.

${ }^{3}$ STERN. De la memoria suelta a la memoria emblemática: hacia el recordar y el olvidar como proceso histórico (Chile, 1973-1998).

${ }^{4}$ BARTHES. El efecto de realidad. La escritura del suceso.

${ }^{5}$ WHITE. Metahistoria. La imaginación histórica en la Europa del siglo XIX.
} 
teatro, quando a mesma questiona suas próprias categorias de análise ${ }^{6}$ e sua relação com a realidade: se seria possível propor um "efeito de ficção" para o teatro em oposição ao "efeito de realidade" de Barthes, por meio do qual se veicularia a ideia de que toda criação dramática ou cênica é pura e mera ficção, quando sabemos que o teatro sempre remete a um "ponto de realidade" - expressão do diretor e dramaturgo chileno Ramón Griffero -, seja esta realidade uma experiência da vida pessoal do criador ou acontecimentos históricos que afetam toda a comunidade. Também, cabe questionar a relação do teatro com o relato e as implicações políticas implícitas nos gêneros - tragédia, comédia, farsa, romance, para voltar a White. Ou, então, sobre o objeto da teatrologia: o teatro, a dramaturgia e a encenação, a vida cultural e social etc.

A partir do antes mencionado, então, o projeto "Teatro e memória. Estratégias de representação e elaboração cênica da memória traumática infantil” tentava uma interseção entre os estudos da memória, os avanços da historiografia do fim do século XX e o teatro - entendido como prática cênica e prática teórica, enquadrando-se em um espaço de pesquisa teórico-cênica que é o Laboratório Teatral da Escola de Teatro UC. O referido laboratório procura ser um espaço de trabalho conjunto para dramaturgos, mas também para teóricos provenientes de distintas disciplinas, que põem em funcionamento "zonas teórico-práticas ou prático-teóricas nas quais as perguntas levantadas partissem da prática, mas onde as respostas não poderiam ser encontradas a não ser como resultado de uma cooperação entre artistas e pesquisadores".?

\section{O PROJETO: AS CRIANÇAS DO GOLPE}

Pois bem, a partir das bases teóricas expostas, surgiu a ideia de trabalhar com a memória de um conjunto de chilenos - crianças em 11 de setembro de 1973 - realizando entrevistas e indagando posteriormente as estratégias de representação e elaboração do trauma histórico que proporciona o trabalho cênico. Cabe ressaltar que as encenações baseadas em testemunhos não são uma novidade no panorama teatral chileno e latinoamericano. Alguns dos trabalhos mais importantes no âmbito nacional são a Trilogía de la memoria de Alfredo Castro, a Trilogía testimonial de Chile de Rodrigo Pérez e as obras de Jacqueline Roumeau Pabellón 2. Rematadas, Colina 1. Tierra de Nadie. Nesse caso, a particularidade do trabalho do laboratório reside no fato de que os testemunhos resgatam experiências de crianças, memórias infantis que em muitos casos se revelaram fragmentadas, incompletas e difusas.

No contexto chileno, onde o golpe de Estado continua sendo um ponto de nãoretorno sobre o qual os governos da transição, e posteriores, têm tratado de negociar uma memória consensual que não se consegue - como já mencionamos -, o tema das crianças em situações de violência política não tem sido tratado a não ser em casos

\footnotetext{
${ }^{6}$ BRALIC. La relación entre arte y cultura: acontecimiento y comunicación.

${ }^{7}$ FERAL. Teoría y práctica más allá de las fronteras, ¿Qué puede (o quiere) la teoría del teatro? La teoría como traducción, Quién tiene necesidad de al crítica, Teatro y sociedad: desde la simbiosis a un nuevo contrato social, p. 23.
} 
muito extremos, deixando totalmente de lado as centenas de milhares de crianças que viveram situações cotidianas e repetidas de temor. Isso em termos gerais. Em particular, duas de nós, que tínhamos, em 1973, a mesma idade dos entrevistados, concordamos que nunca tínhamos conversado com ninguém da família nem com os amigos sobre as experiências daqueles anos. Interessava-nos, então, saber como tinham vivido as crianças - que agora são aqueles que governam o Chile, tendo sedimentado essa experiência em sua conduta adulta - experiências que eu identificava claramente como situação traumática. ${ }^{8}$

O projeto se propôs então como:

Um espaço de trabalho interdisciplinar (teatro, história oral, psicologia) que pesquisasse as possibilidades da arte teatral como espaço de elaboração das dores que arrastamos como sociedade, no entendimento de que tal elaboração devesse permitir que o passado se converta em memória de uma experiência coletiva fundadora sobre a qual possa ser consolidada uma identidade coletiva clara e com projeção no futuro. A pesquisa enfatizará diversos aspectos do relato dos entrevistados, considerando como elementos de igual interesse tanto as lembranças das situações que tiveram que viver e as formas de elaboração discursiva das mesmas (as explicações racionais que eles mesmos se deram sobre o que ocorria) quanto as sensações (medo, tristeza, euforia etc.) que experimentaram e os jogos físicos ou sequências de movimentos repetitivos originados. Em termos metodológicos, o que se propõe é uma pesquisa bidimensional da memória do trauma: por um lado, a do testemunho (a narração do passado) e, por outro, a re-atuação (re-enactment) das marcas que o trauma histórico deixou no corpo (o que se fará tanto no momento das entrevistas como no trabalho com os atores). ${ }^{9}$

\section{Os SONS do Golpe: testemunHOS dAS CRIANÇAS SOB A DITADURA MILITAR}

Este projeto se baseou na memória de 13 adultos entre 30 e 48 anos que concordaram em dar seu testemunho sobre sua infância na ditadura, particularmente na época do

\footnotetext{
${ }^{8}$ Para uma discussão do conceito de trauma, é necessário começar a partir do trauma individual, com FREUD, S. particularmente com "Rememoración, repetición, perlaboración" (1914) e "Duelo y melancolía" (1915), e seguir com CARUTH. Unclaimed Experience: Trauma, Narrative and History; e CARUTH. Trauma: Explorations in Memory; para o trauma cultural, ver ALEXANDER. Towards a Theory of Cultural Trauma; e para uma relação entre psicanálise, história e o papel do historiador perante o trauma, ver: LACAPRA. Escribir la historia, escribir el trauma.

${ }^{9}$ GRASS KLEINER, CONTRERAS, NICHOLLS. Proyecto. VRAID 15/2008. "una instancia de trabajo interdisciplinario (teatro, historia oral, psicología) que investigara las posibilidades del arte teatral como espacio de elaboración de los dolores que arrastramos como sociedad, en el entendido de que dicha elaboración debiera permitir que el pasado pase a constituirse en memoria de una experiencia colectiva fundante sobre la cual pueda consolidarse una identidad colectiva clara y con proyección en el futuro. La investigación pondrá énfasis en diversos aspectos del relato de los entrevistados, considerando como elementos de igual interés tanto los recuerdos de las situaciones que les tocó vivir y las formas de elaboración discursiva de las mismas (las explicaciones racionales que ellos mismos se dieron sobre lo que ocurría) como las sensaciones (miedo, tristeza, euforia, etc.) que experimentaron y los juegos físicos o secuencias de movimientos repetitivos a que dieron origen. En términos metodológicos, lo que se propone es una investigación bidimensional de la memoria del trauma: por un lado, la del testimonio (la narración del pasado) y, por otro lado, la re-actuación (re-enactment) de las huellas que el trauma histórico ha dejado en el cuerpo (lo que se hará tanto al momento de las entrevistas como en el trabajo con los actores)."
} 
golpe de Estado, e, depois, durante os agitados anos 1980, cenário dos protestos nacionais. Trata-se de uma mostra heterogênea, em que a grande maioria provinha de famílias de esquerda ou que pelo menos apoiaram Allende. Uma das motivações do projeto era saber o que aconteceu na ditadura com as crianças que não sofreram uma repressão direta, aqueles que não tiveram dentro de sua família um preso desaparecido ou morto pela ditadura, apesar de que foram incluídos alguns testemunhos de pessoas que tinham tido experiências desse tipo. Sentimos que era necessário um contraponto. Por outro lado, mesmo tendo entrevistado pessoas de classe média e setores populares, a maioria das reflexões e citações correspondem à dos que vinham de áreas populares da cidade. Esta pequena mostra somente nos permitiu realizar um trabalho exploratório, levantar hipóteses, formar imagens, indagar as emoções de nossos entrevistados.

\section{O QUE SIGNIFICOU PARA AS CRIANÇAS VIVER SOB A DITADURA?}

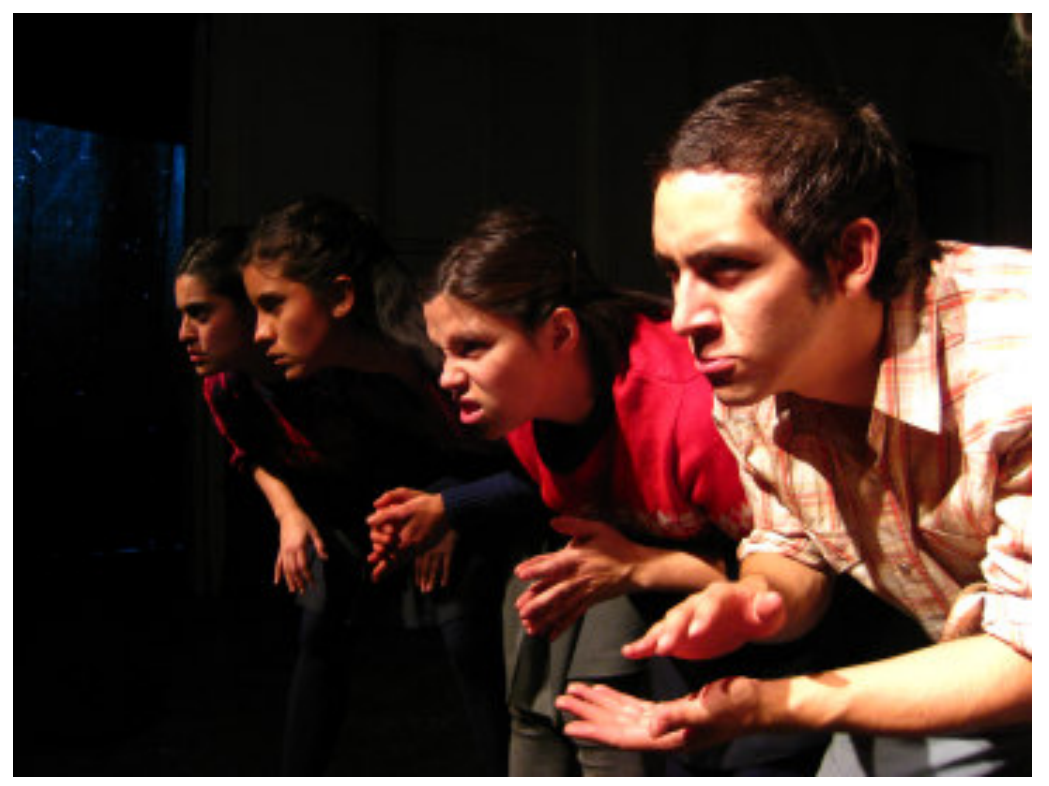

As crianças dos povoados sofreram com a indiscriminada e arbitrária repressão massiva que se desdobrou imediatamente após o dia 11 de setembro de 1973. O golpe e os anos 1980 significaram a presença de militares nas passagens dos povoados, carregando metralhadoras, fazendo rondas noturnas, arrancando os jovens de suas casas, em roupas íntimas, para levá-los ao exército, invadindo casas, caçando militantes, levando alguns e fazendo-os desaparecer. Esse tipo de ação se enquadrava dentro das operações da ditadura em busca de "suspeitos", muito comum após o golpe, procedimento rotineiro até 1975 em setores populares, realizados por forças militares ou policiais, e logo reeditado sob o contexto de protestos em 1984, em que muitos setores de Santiago foram ocupados por militares, por terra e ar, ao amanhecer. No ano de 1986, esta forma de amedrontar a população se intensificou. ${ }^{10}$

${ }^{10}$ LIRA. Psicología de la Amenaza política y del miedo, p. 139-140. 
Como as crianças sabiam da existência da ditadura? Como a vivenciavam? Como a sentiam? Em primeiro lugar, ficavam sabendo "de ouvidos", por meio das conversas dos adultos. Leonardo tinha 8 anos na época do golpe, morava em Quinta Normal e lembra: "Nessa época as crianças não existiam muito. Ficávamos por aí, sempre à espreita. Os adultos não hesitavam em falar das coisas na frente das crianças, porque elas não existiam. Se escutávamos de tudo, e isso também impressionava porque eram mortos, imaginávamos coisas, falavam de mortos em Mapocho, nas ruas (...)."11

O elemento sensorial estava constantemente presente. Durante a noite, as crianças escutavam o barulho dos tiros, o barulho dos militares transitando pelas ruas, o barulho dos aviões ou dos helicópteros e a partir disso se usava a imaginação. Escutavase, no geral não se podia ver: esconder para proteger. Entre os nossos entrevistados, foi comum que relatassem como as janelas deviam ser protegidas com colchas grossas e as luzes apagadas; somente se iluminavam com velas, dormiam nos cômodos do interior da casa, calados, as crianças não deviam fazer barulho; tudo isso para evitar tiros, para evitar as invasões, para não provocar o militar armado.

O mesmo aconteceu para os protestos de rua. Algumas crianças participavam dos protestos no período da tarde como uma brincadeira, para extravasar as tensões; a rua, então, se converteu em um espaço de catarse, ${ }^{12}$ um espaço, por mais contraditório que pareça, de liberdade. Mas outros tinham que ir cedo para suas casas e inclusive para a cama, então, sobrava somente a possibilidade de escutar. Uma testemunha relembra:

Lembro que saíamos pra fazer barulho (...), mas depois tínhamos que ir dormir, mas todo o barulho que havia na rua era como sentir muita gente gritando, choros, tiros no ar. Lembro sempre que sentia que eram muitas pessoas que estavam sentadas e gritavam "vai cair”, mas muita gente, não sei, ficava imaginando que estavam sentadas (...) esses barulhos sempre me levam até essas noites de muito embate, imagina para uma criança estar nesse lugar e não ver, então você começa a imaginar... e (pensava) que em algum momento essas pessoas poderiam entrar, eu sentia de longe, mas que em algum momento poderiam entrar e acabar com tudo, muito forte (...). ${ }^{13}$

Nem todas as crianças que moravam em povoados receberam explicações para suas perguntas sobre o que estava acontecendo durante a ditadura; alguns eram muito pequenos para entender; para outras famílias a comunicação verbal não existia e, portanto, também não era um recurso nessas situações. Desse modo, restava a imaginação. Mas também

${ }^{11}$ Entrevista a Leonardo Fernández, Santiago, 30 junho 2008. "En ese tiempo los niños no existían mucho. Uno estaba por ahí, uno estaba parando la oreja siempre. Los adultos no trepidaban en hablar cosas delante de los niños, porque los niños no existen. Si uno escuchaba de todo y eso también impresionaba porque eran muertos, uno se imaginaba, hablaban de muertos en el Mapocho, en las calles (...)."

${ }^{12}$ Salazar e Pinto falam de festa "catártica". SALAZAR; PINTO. Historia Contemporánea de Chile. Actores, identidad y movimiento, p. 126.

${ }^{13}$ Entrevista a M.G.A., Santiago, 3 julho 2008. "Recuerdo que salíamos a tocar las ollas (...) pero después nos íbamos a acostar, pero todo el ruido que había en la calle era como sentir mucha gente gritando, llantos, balas al aire. Recuerdo siempre que sentía que eran muchas personas que estaban sentadas y gritaban 'va a caer', pero mucha gente, no sé, me imaginaba que estaban sentadas (...) esos ruidos siempre me trasladan a esas noches de mucho enfrentamiento, imagínate para un niño en ese lugar y no verlo, entonces te empiezas a imaginar... y (pensaba) que en algún momento iban a entrar al pasaje esas personas, lo sentía lejano, pero que en algún momento iban a arrasar con todo, muy fuerte (...).” 
havia a experiência direta; houve alguns que sofreram invasões em suas casas - ficando sem seus pais -, outros souberam do desaparecimento e morte de um vizinho e outros experimentaram a prepotência humilhante dos militares.

\section{O QUE SENTIAM AS CRIANÇAS DIANTE DESSE ACÚMULO DE EXPERIÊNCIAS NEGATIVAS?}

Talvez medo seja a palavra mais recorrente quando os entrevistados falam de suas experiências durante a ditadura, mas também são recorrentes as palavras "susto, terror, choro, horror, silêncio, angústia, espanto, brutalidade", mas não devemos nos esquecer de que essas palavras surgem de perguntas concretas sobre o golpe e o período de protestos.

Roberto (Nueva la Habana) conta que nos primeiros dias após o golpe, quando escurecia e começavam os tiros, seu medo era tanto que "honestamente, tinham que me colocar num penico, ${ }^{14}$ me dava pavor". ${ }^{15}$ Cláudio expressou seu medo por meio de gritos quando invadiram a sede do clube comunitário do povoado de José María Caro e o colocaram em um ônibus, somente para abandoná-lo no caminho uns minutos depois, já que o preso - seu pai - andava com uma criança. ${ }^{16} \mathrm{E}$ é aqui onde se tece uma rede de imagens, fragmentos de conversas adultas, imaginação, que permitem às crianças, de alguma maneira, dar sentido ao que estavam vivendo, que se qualifica como algo de grande dimensão, como algo pesado, como algo violento, que transtorna o cotidiano e que além do mais provoca muito temor. Marisol (Pudahel) tinha 4 anos na época do golpe e se lembra que "as pessoas estavam loucas nesse dia, que ela não entendia nada, que sua mãe chorava e que todos estavam assustados". ${ }^{17}$ Doris, sua irmã de 6 anos, também via sua mãe chorar mas perguntava e a resposta era "não é nada minha filha" e todos choravam. Então, Doris "imaginava que havia um terremoto, um tremor forte porque essa era a sensação que vivia. Ou que um avião tinha caído - porque em algum momento lhe disseram isso - e os militares estavam cuidando dela e de suas irmãs". ${ }^{18} \mathrm{O}$ medo estava unido ao silêncio, ir cedo para a cama, "shhh", não falar alto para que os "milicos" não escutassem. Doris e Marisol se lembram: "Dormíamos todos no quarto menor (...) e eu acho que por volta das sete horas já estávamos escondidas ali no quarto, e tudo escuro, não podíamos fazer bagunça, fazíamos tudo caladinhas; minha mãe nos dava comida caladinhas, dizia, por favor, não falem, não chorem, não gritem, nada (...).”19 Daniela

\footnotetext{
14 “a mí honestamente, me tenían que poner una pelela , me espantaba". "Pelela”: expressão popular chilena para penico.

${ }^{15}$ Entrevista a Roberto Cofré, Santiago, 1 setembro 2008.

${ }^{16}$ Entrevista a Claudio Pérez, Santiago, 21 agosto 2008.

17 "la gente andaba como loca para ese día, que ella no entendía nada, que su mamá lloraba y que la gente estaba asustada".

18 "imaginaba que había un terremoto, un temblor fuerte porque esa era la sensación que vivía. O que se había caído un avión- porque en algún momento así le dijeron- y los militares las estaban cuidando a ella y a sus hermanas".

${ }^{19}$ Entrevista a Marisol e Doris Pacheco, Santiago, 28 agosto 2008. "Dormimos todos en la pieza chiquitita (...) y yo creo que como a las siete de la tarde ya estábamos escondidas ahí en la pieza, y todo a oscuras, no podíamos meter bulla, todo calladito lo hacíamos; mi mamá nos daba comida calladitas, decía por favor no hablen, no lloren, no griten, nada(...).”
} 
tinha 11 anos em março de 1985 quando sequestraram José Manuel Parada e Manuel Guerrero do Colégio Latino-americano de Integração, onde ela estudava, sendo companheira de curso e amiga de Javiera Parada. ${ }^{20}$ Daniela se lembra do medo, do temor, da angústia, mas o que mais chama a atenção é a lembrança do temor de perder os limites, "as coisas mais atrozes podiam acontecer", lembra, "e não havia muito o que se pudesse fazer para impedir isso, sua sorte não te pertencia, pertencia ao outro, o poder é do outro". ${ }^{21}$

Para as crianças da ditadura entrevistadas, a ameaça e o medo foram experiências concretas, em alguns casos marcaram um acontecimento difícil de apagar da memória, em outros foram experiência cotidianas, aceitas pela força do costume. Estas vivências tornaram as crianças mais vulneráveis? O medo se instaurou em sua identidade, articulando sua condição no mundo, sua vida futura e as formas de relacionamento com os outros? Andréa tinha 2 anos na época do golpe, sua família era de esquerda e morava em um bairro residencial de Las Condes. Andréa afirma: "É muito esquisito porque eu gostei muito da minha infância apesar de tudo, tive uma infância super feliz." 22 No entanto, Andréa se lembra dos bombardeios de Tomás Moro, abraçando a barriga de sua mãe que estava grávida, recorda a angústia de seus pais pelo desaparecimento e prisão de muitos de seus amigos, lembra recorda tensão de seu pai por não poder voltar ao trabalho durante três meses, recorda que tinha que ficar calada quando um "tio" se escondia em sua casa, guardando o segredo com uma adulta e lembra de diversos momentos em que viveu o silêncio. Por exemplo, quando cantou no supermercado "O povo unido jamais será vencido" 23 alguns dias após o golpe e sua mãe lhe disse para ficar calada; ou em vários momentos em que, na escola que frequentava, teve que estabelecer uma clara separação entre o espaço público e o espaço privado, porque nem todos pensavam como ela e sua família.

Assim como ela, a maioria dos entrevistados lembra sua infância como uma época feliz - ou pelo menos não triste -; e em geral não se pode dizer que existe neles muito esquecimento intencional; há, na verdade, uma mescla experiências de temor e ameaça com outras, cheias de alegrias, de vitalidade, de felicidade. Trata-se de jogos infantis.

\footnotetext{
${ }^{20}$ José Manuel Parada, Santiago Nattino e Manuel Guerrero foram sequestrados em março de 1985, sendo posteriormente degolados por agentes da Dirección de Comunicaciones de Carabineros (DICOMCAR). Javiera Parada é a filha de José Manuel Parada.

${ }^{21}$ Entrevista a Daniela Zenteno, Santiago, 14 setembro 2008. "las cosas más atroces podían ser" (...), "y no había mucho que uno pudiera hacer que impidiera eso, tu suerte no estaba puesta en ti, sino en otro, el poder es de otro".

${ }^{22}$ Entrevista a Andrea Ubal, Santiago, 7 julho 2008. "Es bien raro porque a mí me gustó mucho mi niñez a pesar de todo, yo tuve una niñez súper feliz."

${ }^{23}$ Canção chilena de Sergio Ortega e o grupo Quilapayún, gravada durante o governo da Unidade Popular e muito popular entre seus adeptos.
} 


\section{Os Jogos}

As crianças continuavam brincando, nas casas, quando havia toque de recolhida, e depois, paradoxalmente, a rua continuou sendo o espaço por excelência, destinado aos jogos infantis, provavelmente porque os espaços eram pequenos e as famílias numerosas; "apropriava-se" da rua. Os jogos tinham todos a mesma característica: eram da "patota", ${ }^{24}$ da turma, ao ar livre. Eram os tradicionais: "papaya", ${ }^{25}$ soltar papagaios em setembro, brincar de bete, de briga de galo, de queimada, de esconde-esconde, de pega-pega, de bolinhas de gude, jogar futebol, e a isso se somava a imaginação e a criatividade das crianças. ${ }^{26}$ Doris e Marisol se lembram de sua infância com suas outras duas irmãs. "Como era um povoado, não havia ruas pavimentadas, então fazíamos o seguinte: poças de lama e aí brincávamos, ficávamos completamente sujas (...) lembro que tínhamos galinhas e dávamos banho nelas (...) lembro que uma vez brincamos de índio e adivinha o que fizemos?: uma fogueira debaixo da mesa." 27

\section{Trauma?}

De uma maneira geral, poderíamos dizer que muitos dos personagens entrevistados enfrentaram situações que podemos qualificar de traumáticas, mas o certo é que suas vidas não estão marcadas pelo trauma. Como se explica isso? As crianças de nossa mostra vivenciaram a repressão. Mas, apesar disso, não houve uma ruptura significativa que modificasse suas vidas por completo, que as inquietasse, porque não houve mortes e desaparecimento de um familiar do círculo mais íntimo, mas, além disso, porque houve uma resposta do ambiente mais próximo, da família, dos companheiros, daqueles que compartilhavam o ideal político da família. ${ }^{28}$ Talvez não houve muita verbalização, mas sim proteção, apoio, o que permitiu a essas crianças seguir adiante com suas vidas promovendo uma espécie de integração entre as experiências horríveis que vinham do contexto político e a experiência acolhedora da família, da rua, que permitia a liberdade, do jogo criativo entre companheiros, da fuga da rotina e da disciplina da ditadura. ${ }^{29}$

Quando perguntei a Daniela qual seria o gesto que descreveria o período de sua infância ela respondeu: "um abraço de minha mãe"; ${ }^{30}$ outra testemunha, por outro lado,

24 "Patota": expressão popular chilena que significa grupo.

${ }^{25}$ Jogo infantil que utiliza pedras.

${ }^{26}$ Trata-se de alguns jogos tradicionais, outros mais modernos, que foram desaparecendo do cotidiano das crianças chilenas urbanas.

${ }^{27}$ Entrevista a Marisol e Doris Pacheco citada. "como era una población no habían calles pavimentadas, qué hacíamos nosotras: pozas de barro y ahí jugábamos, nos embarrábamos enteras (...) me acuerdo que teníamos gallinas y nosotras bañábamos a las gallinas (...) me acuerdo una vez que jugamos a los indios y iadivina qué hicimos?: una fogata debajo de la mesa".

${ }^{28}$ CYRULNIK. El murmullo de los fantasmas, p. 33

${ }^{29}$ FERENCZI en DIAZ. Efectos traumáticos de la Represión Política en Chile: Una experiencia clínica.

${ }^{30}$ Entrevista a Daniela Zenteno citada. "Un abrazo de mi mamá". 
não falou de seus medos com seus pais, mas lembra: "Sabia que podia contar com eles e que me protegiam, sempre tive isso bem claro." ${ }^{11}$

\section{REFLEXÃo SOBRE A MEMÓRIA CULTURAL OU SOCIAL DAS CRIANÇAS SOB DITADURA}

Não há, ao que parece, trauma individual em nossas crianças, mas o que acontece no nível social? Sob o ponto de vista das ciências sociais considera-se que o golpe de Estado no Chile produziu a ruptura mais profunda que nosso país experimentou no século XX. Lechner e Guell - citando outros estudos - afirmam que "o 11 de setembro é vivido pelos chilenos como uma ruptura que - tanto na vida pessoal como na do país - marca um corte profundo entre o antes e o depois". ${ }^{32}$ Os autores fazem alusão a um trauma social ou cultural, como definido por outros especialistas; esse trauma que se instala na sociedade em seu conjunto, que se relaciona ao medo, à desconfiança em relação ao outro, à perda do sentido de comunidade em tantos chilenos, com a polarização; ou seja, com a atribuição de sentido que a sociedade lhe dá às experiências vividas pósgolpe, muitas das quais também têm a ver com a criação de um clima psicológico destinado a provocar angústia e medo. $\mathrm{O}$ que mais poderia ser o barulho de aviões e helicópteros sobrevoando os povoados ou bairros residenciais, que um general da ditadura reconheceu como uma ação destinada a criar um efeito amedrontador que permaneceria na cabeça dos chilenos por muito tempo? Estamos diante de um medo coletivo, de uma ameaça generalizada que surge dos aparatos de segurança do regime ditatorial. ${ }^{33}$

E é nesse ponto que queremos refletir um pouco sobre os testemunhos, porque, apesar de que a vida continuou para essas crianças e trouxe porções importantes de felicidade, em famílias protetoras, estruturadas familiarmente, a vida se modificou provavelmente de maneira inconsciente para muitas delas. $O$ medo, por exemplo, se instalou para ficar. Como se explica que Emilio, hoje, em seus 48 anos, sinta terror diante de um soldado, terror percebido pelas filhas e transmitido inconscientemente para uma delas? ${ }^{34}$ Ou que Daniela, na última comemoração do 11 de setembro, quando o centro estava cheio de militares vestidos com fardas de guerra, não se sentisse à vontade e sentisse medo também. ${ }^{35}$ Ou que Mário, ao ler o Relatório Valech, ${ }^{36}$ em que aparece seu pai, ou ao trabalhar em cursos de percepção da Escola de Teatro UC, escute testemunhos de horror, e a raiva e o medo reapareçam nele. ${ }^{37} \mathrm{Ou}$ que Leonardo,

\footnotetext{
${ }^{31}$ Entrevista a M.G.A. citada. "Sabía que podía contar con ellos y me protegían a mi, siempre lo tuve más que claro."

${ }^{32}$ LECHNER; GUELL. Construcción social de las memorias en la transición chilena, p. 30. "el 11 de septiembre es vivido por los chilenos como una ruptura que - tanto en la vida personal como en la del país - marcan un corte tajante entre antes y después".

${ }^{33}$ LIRA. Psicología de la Amenaza política y del miedo, p. 8.

${ }^{34}$ Entrevista a Emilio Soto, Santiago, 12 setembro 2008.

${ }^{35}$ Entrevista a Daniela Zenteno citada.

${ }^{36}$ Relatório da Comissão Nacional sobre Prisão Política e Tortura, que cobre o período compreendido entre 11 de setembro de 1973 e março de 1990. Ficou conhecido em novembro de 2004.

${ }^{37}$ Entrevista a Mario Costa, Santiago, 8 julho 2008.
} 
lembrando o barulho dos aviões e helicópteros que faziam voos rasantes, de maneira tangencial mencione: "Talvez a gente tivesse medo dos aviões, o barulho dos aviões, talvez ainda me dê, alguma coisa tenho com os aviões que é difícil sair de mim." 38

Como sociedade, não trabalhamos a memória dolorosa, quebrada e dilacerada de nosso passado recente, e as crianças da nossa mostra não escapam disso. Impôs-se o silêncio, no momento da infância, e permanece até um presente no qual não se esboça um caminho possível de comunicação de nossas memórias dolorosas.

Refletindo após um longo silêncio sobre o sequestro de José Manuel Parada e Manuel Guerrero, Daniela afirma: "acontece que enquanto conversávamos havia muitas lembranças que não apareciam há muito tempo, acho que também há uma parte de mim que tenta não remover muita lembrança e agora me dou conta de que conversamos. Acontece que tenho, na hora de voltar a essa época, imagens e sentimentos associados, mas há outras que estão super apagadas, que acho que têm a ver com mecanismos de sobrevivência porque são fortíssimas". ${ }^{39}$ Roberto, por outro lado, lembra ter visto os cadáveres na rua - calculava uns dez -, mas quando lhe perguntamos o que sentiu, respondeu que não tem lembranças de seus sentimentos. ${ }^{40}$ Mario, por outro lado, conta que seu pai conversou com ele sobre sua experiência como prisioneiro no acampamento de prisioneiros políticos Chacabuco, somente quando saiu seu nome no Relatório Valech em 2004 e estava com ele em mãos. Então contou, mas não falou da tortura e ninguém lhe perguntou. ${ }^{41}$

As crianças de nossa mostra puderam falar do que acontecia, nem sempre encontraram respostas, mas conseguiram dar significado à experiência, no entanto ficaram muitas zonas obscuras, desfiguradas, na memória. Fica a sensação, após ler os testemunhos, de que há memórias asfixiadas, apagadas, sepultadas, embora haja algumas que foram muito mais processadas e trabalhadas. Hoje essas crianças são adultas e nos perguntamos se não foram submetidas ao silêncio, à obrigação de se calar, ao não encontrar ouvidos para escutá-las.

\footnotetext{
${ }^{38}$ Entrevista a Leonardo Fernández citada. "Quizá a uno le daba miedo los aviones, el ruido de los aviones, quizás todavía me da, algo tengo con los aviones que me cuesta desentrañar."

${ }^{39}$ Entrevista a Daniela Zenteno citada. "me pasa que mientras conversábamos habían hartos recuerdos que no hacía hace mucho tiempo, creo que también hay una parte de mí que intenta no remover mucho recuerdo y me doy cuenta ahora que conversamos. Me pasa que tengo, al momento de ir a esa época, imágenes y sentimientos asociados, pero hay otras que están súper borradas, que creo que tiene que ver con mecanismos de sobrevivencia porque son re-fuertes".

${ }^{40}$ Entrevista a Roberto Cofré citada.

${ }^{41}$ Entrevista a Mario Costa citada.
} 


\section{Pajarito nuevo la lleva: do testemunho ao palco}

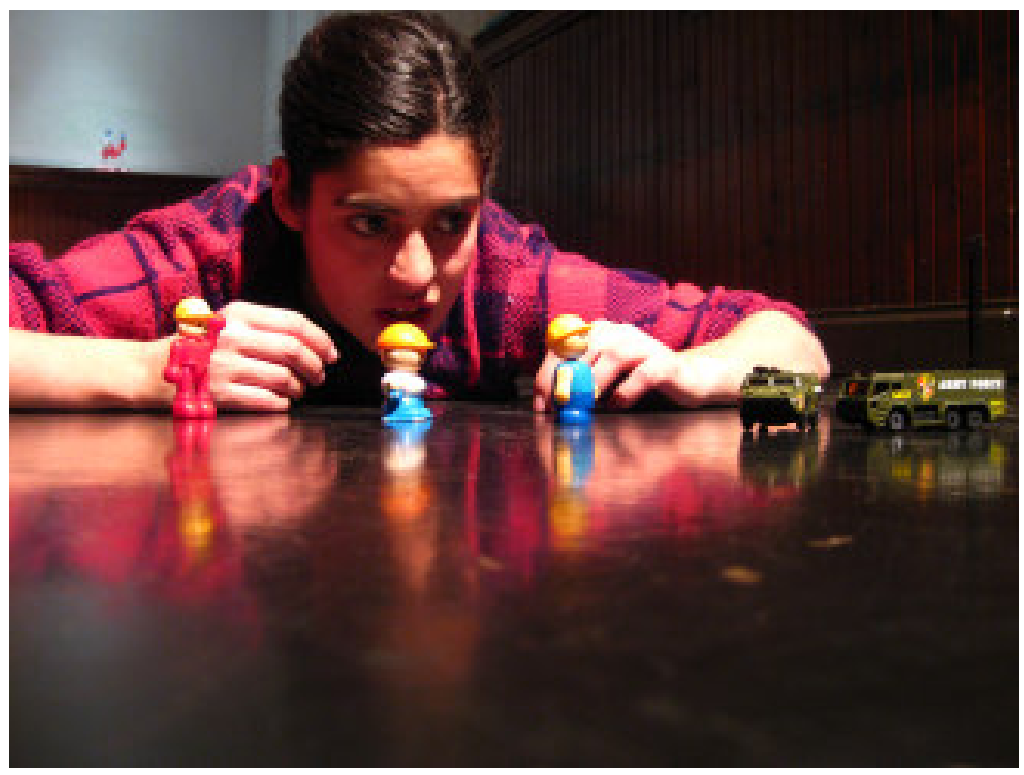

O principal desafio do trabalho cênico que este laboratório enfoca é a montagem teatral das lembranças, sensações e também, porque não dizer, dos esquecimentos que ficaram em evidência nas entrevistas. Este trabalho revelou-se árduo e intenso, sobretudo pela proximidade dos testemunhos que descreviam um passado recente de nossa história. Durante todo o processo procuramos a distância adequada para contar as histórias e os relatos dos entrevistados. A posição que assumimos se distanciou de qualquer pretensão de objetividade ou da intenção de representação mimética destes fragmentos de memórias; preferimos nos posicionar como mediadores dos relatos, como porta-vozes desse passado, que na opinião dos próprios entrevistados ainda permanecia coberto por um véu de silêncio e esquecimento. Pajarito Nuevo la Lleva não é então, uma reexumação passiva de memórias alheias; trata-se de uma interpretação de sujeitos críticos e pensantes do passado de outros sujeitos críticos e pensantes. Como interpretação, implica certa "manipulação" do material testemunhal: exige a seleção do que finalmente se mostrará em público e, portanto, a ênfase de alguns aspectos e a narcotização de outros.

A diretora e o elenco do laboratório tiveram acesso à experiência das testemunhas através de dois tipos de textos: os registros audiovisuais das entrevistas e suas transcrições. O trabalho de pesquisa cênica consistiu então em traduzir esses textos (escritos e audiovisuais) no que poderíamos definir como uma prática perfomativa. ${ }^{42}$ Para realizar esta operação de tradução tivemos que aplicar o que Umberto Eco denomina uma

\footnotetext{
${ }^{42}$ Uma prática performativa se define por 4 características: 1 . Trase-se de uma interação em ato e ao vivo entre pelo menos dois participantes, um performer e uma testemunha. 2. A ação e presença do performer tem por objetivo produzir um efeito estético. 3. Os participantes na prática performativa se encontram em uma situação assimétrica de apreciação: o performer faz e a testemunha aprecia. 4 . Na interação, o corpo do performer se "constrói" de um modo não cotidiano por meio de técnicas ou simplesmente graças à ostentação de sua presença. (CONTRERAS. Il corpo in scena: indagine semiotica sullo statuto del corpo nella prassi performativa, p. 82-96).
} 
interpretação intersemiótica, ou seja, quando se interpretam signos de um certo sistema semiótico através de signos de outro sistema semiótico. ${ }^{43}$ Tanto as transcrições (textos verbais escritos) quanto os registros audiovisuais (compostos por imagens e sons em sequência) tiveram que se transformar em uma prática performativa, ou seja, em ações dos atores em cena realizadas diante dos espectadores. Para serem transformados em material performativo, os testemunhos se fizeram corpo, ação e presença para adquirir a validade teatral.

Essa mudança, certamente nem automática e nem imediata, implica certa licença interpretativa que requer os dois tipos de operações que Eco definiu como fazer ver o não dito e não fazer ver o dito. ${ }^{44}$

Converter o testemunho em prática performativa exige fazer ver o não dito: há detalhes que o relato verbal pode omitir, mas que a encenação não pode não mostrar. Por exemplo, quando Jenny conta como seu pai foi agredido por militares na praça de seu bairro diz: "tínhamos ido comprar pão e meu pai andava de muletas e eu como se nada estivesse acontecendo, caminhando com ele, carregando a sacola de pão e de repente - na praça se juntaram muitos militares - e começaram a correr, e lembro muito bem que batem no meu pai com cassetete e ele cai". ${ }^{45}$ Neste forte relato sobre a agressão que sofreu seu pai, Jenny não especifica quantos militares estavam na praça, eram três, quatro, quinze? A transformação performática exige dizer aquilo que não se disse, é inevitável realizar uma aposta interpretativa que especifique (que mostre no palco) o número de militares que participaram desse ato vexatório. Obviamente o efeito teatral e também a compreensão do passado relatado muda se no palco aparecem dois militares ou vinte.

Outra operação complementar é a seleção do complexo e rico universo das entrevistas que implica em não fazer ver o dito, ou melhor, não fazer ver (todo) o dito. Os testemunhos continham um universo de informação tanto no nível do conteúdo (os detalhes dos relatos, a narrativa do passado) quanto no nível da expressão (o modo como se contavam as lembranças, quais gestos acompanham o relato verbal, as inflexões e entonação da voz, os percursos dos olhares, etc.). Uma encenação que abrangesse todo este universo é francamente impensável, a interpretação intersemiótica demandou uma decisão sobre quais aspectos dos testemunhos seriam reportados na prática performativa. A seleção ocorreu nos dois níveis mencionados: no nível do conteúdo e no nível da expressão.

No nível do conteúdo: as isotopias

${ }^{43}$ ECO. Dire quasi la stessa cosa, p. 236.

${ }^{44}$ ECO. Dire quasi la stessa cosa, p. 327-334. "hacer ver lo no dicho" y "no hacer ver lo dicho".

45 "habíamos ido a comprar pan y mi papa andaba con muletas y yo como si nada, caminando con él, trayendo la bolsa del pan y de repente ya -en la plaza se juntaban todo lo que era militar-y empezaron a correr, y me acuerdo muy bien que le botan el bastón a mi papi y él se cae, y garabatos”. 


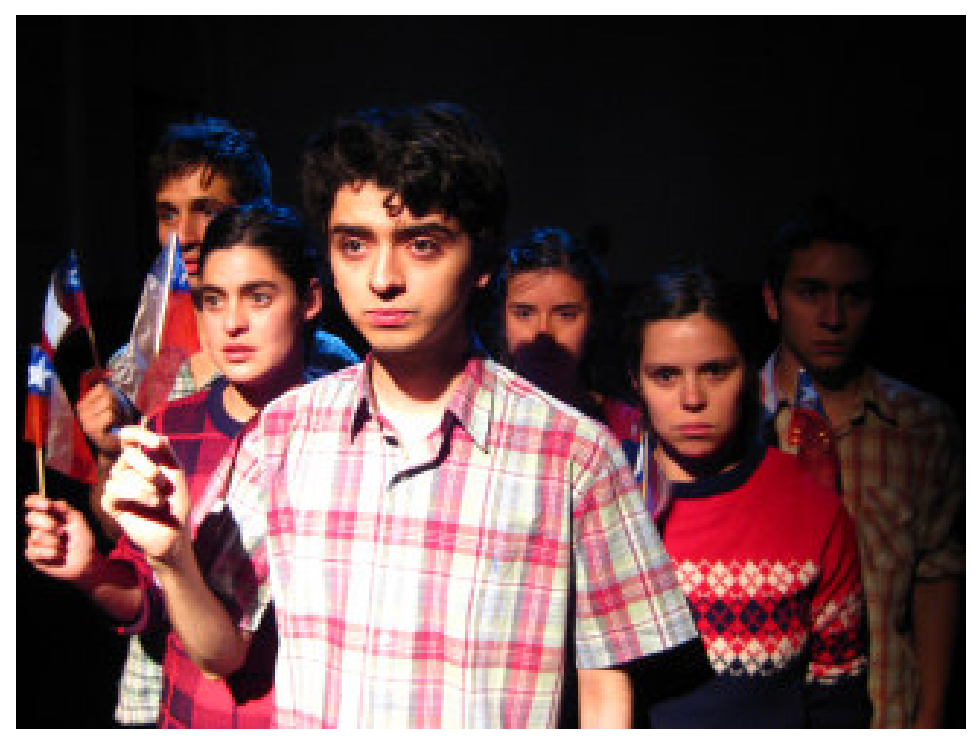

A seleção do conteúdo para a transformação realizou-se mediante a identificação das isotopias ${ }^{46}$ mais recorrentes nos testemunhos. Como mencionamos anteriormente, algumas das recorrências nas entrevistas são:

- os jogos infantis (na rua, comunitários);

- o medo;

- o som dos helicópteros; e

- não saber o que está acontecendo, não ter explicações dos pais.

A seleção das isotopias abrange aqueles temas que se repetiam transversalmente nos testemunhos. Alguns dos espectadores comentaram como as cenas retratavam verossimilmente "o estado de ânimo" da época. Pensamos que, entre outras coisas, uma adequada seleção das isotopias permitiu que os expectadores que também eram crianças nessa época se identificassem e que a ação em cena ecoasse em suas próprias memórias, talvez porque as isotopias identificadas correspondem aos elementos mais proeminentes na memória cultural.

\section{AS FORMAS DE EXPRESSÃO}

A transformação não só se realizou no nível do conteúdo, mas também se aplicou uma seleção sobre as formas de expressão dos testemunhos. Mais além ou mais aquém do conteúdo, pareceu-nos particularmente relevante dar conta de como se narram as memórias e por meio de quais estratégias se constrói o próprio passado. Selecionamos dois aspectos que nos pareceram cruciais nos testemunhos:

${ }^{46}$ Uma isotopia é uma redundância de semas que dá coerência a uma determinada configuração textual (ECO. Semiotica e filosofia del linguaggio). 


\section{A SONORIDADE DAS VOZES ORIGINAIS}

Tão importante como o conteúdo dos testemunhos eram as vozes dos entrevistados, que, por meio de titubeios, sussurros, choros e risos, conseguiam relatar seu passado. A leitura das transcrições era uma experiência completamente distinta de escutar as vozes reais das testemunhas, que davam uma densidade e autenticidade ao relato dificilmente reproduzível a partir de uma técnica de atuação. Pareceu-nos imperativo compartilhar com os espectadores a comovente experiência de escutar os testemunhos em sua forma original, de sentir a voz real de quem narrava seu passado.

Em primeira instância pensamos em reproduzir a voz dos atores como um som na sala, mas descartamos esta opção, já que nos pareceu que desvirtuaria uma das características dos testemunhos: sua intimidade. Os testemunhos nascem na segurança de uma conversa entre duas pessoas, que a amplificação do som perverteria, criando uma distância entre o espectador e a voz narradora. Foi assim que tivemos a ideia de que cada espectador tivesse um dispositivo de áudio pessoal (um discman) que lhe permitisse escutar fragmentos de distintos testemunhos na intimidade que proporcionam os fones de ouvido.

O registro de áudio que os espectadores escutavam continha uma edição de fragmentos dos testemunhos, duas canções e alguns momentos de silêncio que coincidiam com as cenas "faladas" (ou seja, quando os atores proferiam textos verbais, a gravação continha silêncio). Assim, as vozes provinham alternadamente do palco e das gravações; de maneira alternada o espectador escutava as vozes dos atores e as vozes originais das testemunhas. Essa estratégia permitiu revelar o dispositivo teatral, lidando a cada momento com dois níveis do trabalho: os testemunhos originais e a operação de interpretação (intersemiótica) que resultou na prática performativa.

\section{A Multiplicidade}

O segundo aspecto trabalhado no nível da expressão se refere à multiplicidade e heterogeneidade dos testemunhos. Se as isotopias tendiam a um movimento homogeneizador que procurava recorrências nas entrevistas, no nível da expressão parecia-nos fundamental resgatar a heterogeneidade dos testemunhos, que, mais além dos aspectos coincidentes, envolviam necessariamente uma individualidade do sujeito que reconstruía seu passado.

Isso foi transformado em uma encenação através da incorporação de distintas faixas de áudio. Os espectadores podiam eleger se escutavam o registro A ou B, e de acordo com o que escolhiam, escutavam versões diferentes do que acontecia no aqui e agora da performance. Pareceu-nos um modo adequado para multiplicar a experiência individual dos espectadores com relação à performance. Ao invés de dirigir-se à construção de um público homogêneo, quisemos produzir uma multiplicidade de olhares, o que, em certo sentido, corresponde aos modos de funcionamento e reconstrução da memória e da história. Cada espectador podia interpretar o que via de acordo com o que lhe era disponibilizado para escutar (o que tinha escolhido sem saber as 
consequências de sua escolha), assim como cada sujeito social interpreta o passado e a história a partir dos referentes aos quais acede. ${ }^{47}$

\section{O CORPO DO ATOR COMO ELO ENTRE A MEMÓRIA COLETIVA E INDIVIDUAL}

Um dos aspectos de destaque do trabalho do laboratório se refere à transformação dos testemunhos em ação encarnada dos atores e atrizes, operação que exigiu um apelo à memória pessoal dos atores. $\mathrm{O}$ trabalho do laboratório nos permitiu constatar que sem esta chamada à memória individual, a representação desses aspectos da coletividade ficaria truncada e provavelmente não seria reconhecida pelo público. Como explica Ornella de la Vega, a memória cultural se ativa no corpo dos atores e dos espectadores a partir da passagem pela memória pessoal dos atores. ${ }^{48}$ É o corpo que atua, então, como elo entre os aspectos da memória da coletividade e a memória individual em um movimento caleidoscópico em que os aspectos individuais e coletivos, pessoais e culturais vão sendo definidos, modificados e construídos em um movimento dinâmico.

O trabalho com a memória pessoal dos atores é uma técnica que foi sistematizada em primeira instância por Stanivslasky e que adquiriu distintas formas segundo diversas ênfases técnicas. $\mathrm{O}$ aspecto da memória que trabalhamos no laboratório é principalmente de índole corporal, no sentido de uma memória que se aloja no corpo e que se reativa na ação. Mais do que solicitar a memória emotiva ou narrativa dos atores, o trabalho cênico se centrou em recuperar, através da ação, aquela memória que habita o corpo e que às vezes resulta tão difícil de desentranhar. Este tipo de trabalho tem seus antecedentes na técnica das ações físicas (Grotowski), mas se desconecta desta porque explora as articulações estéticas e sensoriais, que, inclusive, prescindindo de uma narração, podem se depositar nos corpos. ${ }^{49}$ Se o corpo lembra, a ação do ator se torna densa, adquire peso e autenticidade. Isso permite que a prática performativa tenha uma eficácia simbólica que obtêm uma espécie de contágio entre o corpo vivo dos atores e atrizes e o dos espectadores. ${ }^{50}$

\section{Conclusões: MEMÓRIA, hISTÓRIA e PERFORMATIVIDADE}

O trabalho de encenação dos testemunhos implica dar ao passado uma nova vida para transmiti-lo no acontecer de um presente que se compartilha no aqui e agora da performance. Trata-se, nesse sentido, de uma estratégia que privilegia o que Diana Taylor denomina repertório, ou seja, aquele tipo de memória que não pertence ao âmbito do arquivo ou do documento, mas sim que se transmite a partir da ação encarnada dos sujeitos. Taylor explica que as performances são instâncias privilegiadas para conservar

\footnotetext{
${ }^{47}$ DEMARIA. Semiotica y memoria. Analisi del post-conflito.

${ }^{48}$ DE LA VEGA. Memoria e identidad del actor como herramienta de construcción dramática, [s. p.].

${ }^{49}$ CONTRERAS. Il corpo in scena: indagine semiotica sullo stauto del corpo nella prassi preformativa.

${ }^{50}$ CONTRERAS. Práctica performativa e intercorporeidad.
} 
a memória de repertórios, uma memória que habita o corpo dos participantes e se cristaliza em gestos, vozes e movimentos que se transmitem na co-presença própria da performatividade e que não podem ser recuperados no arquivo. ${ }^{51}$

A partir deste ponto de vista, Pajarito Nuevo la Lleva pode ser considerada como uma instância de transformação de documentos em repertório. Esta estratégia performativa de publicação e ostentação das memórias individuais serve para dar conta de uma vivência pessoal, mas também para construir o passado coletivo. Através da performance o passado se faz visível adquirindo novos valores e sentidos. A transmissão do testemunho implica na expansão das testemunhas: aqueles que assistem ao Pajarito Nuevo la Lleva se convertem em testemunhas desse passado tão pessoal e tão coletivo ao mesmo tempo. Experiências como Pajarito Nuevo la Lleva servem a um duplo propósito de contar a história e de representá-la ativando o repertório, que, ao representá-la, constrói e a transforma.

A memória é por definição dinâmica e vai dando um novo significado aos fatos ocorridos através do tempo; mas a sociedade deu espaços e ouvidos para que as memórias ocultas das crianças da ditadura pudessem ir ganhando um novo significado? Houve a possibilidade para que hoje estas memórias saiam à luz e dialoguem com as "memórias fortes", ${ }^{52}$ com as memórias antagônicas, com as memórias paralelas sobre o acontecido? Parafraseando Dori Laub, quem nos lembra que: “O não contar' a história serve para perpetuar sua tirania"; ${ }^{53}$ poderíamos dizer que o não representar a história perpetua ainda mais essa tirania.

Tradução: Cristiano Silva de Barros

RESUMEN

El presente artículo da cuenta de una investigación escénica llevada a cabo a partir de los testimonios recogidos entre quienes fueron niños para el Golpe de Estado (Chile 1973) y para el período de protestas de los años '80. Los objetivos del proyecto fueron rescatar una memoria que no ha sido considerada oficialmente como parte del proyecto de reconciliación y reconstrucción nacional, y revisar sus posibilidades de traducción performática para propender así a la elaboración colectiva del trauma cultural que significó la dictadura el Chile.

\section{Palabras-CLAVE}

Teatro. Memoria. Infancia.

${ }^{51}$ TAYLOR. Archive and repertoire. TAYLOR. El pasado, instrucciones de uso. Historia, memoria, política.

${ }^{52}$ TRAVERSO. El pasado. Instrucciones de uso. Historia, memoria, política, p. 48-56.

${ }^{53}$ LAUB. An Event without a Witness: Truth, testimony and Survival, p. 79. "'El no relatar' la historia sirve para perpetuar su tiranía." 


\section{REFERÊNCIAS}

ALEXANDER, J. Towards a Theory of Cultural Trauma. In: ALEXANDER, J. et al. Cultural Trauma and Collective Identity. EEUU: University of California Press, 2004.

AUGÉ, M. Las formas del olvido. Barcelona: Gedisa, 1998.

BARTHES, Roland. El efecto de realidad, la escritura del suceso. In: . El susurro del lenguaje. Barcelona, Paidós. p. 179-195.

BRALIC, Cecilia, La relación entre arte y cultura: acontecimiento y comunicación. Cátedra de Artes, n. 1, p. 99-107, Facultad de Artes PUC, Santiago del Chile, 2005.

CARUTH, C. Trauma: Explorations in Memory. EEUU: The Johns Hopkins University Press, 1995.

CARUTH, C. Unclaimed Experience: Trauma, Narrative and History. EEUU: The Johns Hopkins University Press, 1996.

CONTRERAS, María José. Práctica performativa e intercorporeidad. Apuntes, n. 130, Escuela de Teatro Pontificia Universidad Católica de Chile, Santiago del Chile, 2008. No prelo.

CONTRERAS, María José. Il corpo in scena: indagine semiotico del corpo nella prassi performativa. 2007. 278 f. Tese (Doutorado em Semiótica) - Universidade de Bolonha, Itália, 2007.

CYRULNIK, Boris. La Maravilla del dolor. El sentido de la resiliencia. Barcelona: Granica, 2001, 211p.

CYRULNIK, Boris. El murmullo de los fantasmas. Barcelona: Gedisa Editorial, 2003. 251p.

DE LA VEGA, Ornella. Memoria e identidad del actor como herramienta de construcción dramática. 2008. 239f. Tesis (Magíster en Dramaturgia Corporal) - Universidad Finis Terrae, Chile, 2008.

DEMARIA, Cristina. Semiotica y memoria. Analisi del post-conflito. Roma: Carocci Editore, 2006. 218p.

DEMARIA, Cristina. Reconciliation and Forgiving: The Power of Happy Memory. GOH, C.; B. McGUIRK (Ed.). Happiness and Postconflict. Nottingham: Critical, Cultural and Communications Press, 2007. p. 55-73.

ECO, Umberto. Semiotica e filosofia del linguaggio. Turín: Einaudi, 1984. 318p.

ECO, Umberto. Dire quasi la stessa cosa. Esperienze di traduzione. Milán: Bompiani, 2003.391p.

FÉRAL, Josette. Teoría y práctica más allá de las fronteras, ¿Qué puede (o quiere) la teoría del teatro? La teoría como traducción, Quién tiene necesidad de al crítica, Teatro y sociedad: desde la simbiosis a un nuevo contrato social. In: - Teatro, teoría y práctica: más allá de las fronteras: Buenos Aires, Galerna, 2004. p. 15-24, 35-85.

FERENCZI, S. (1934) citado em: DÍAZ, Margarita. Efectos traumáticos de la Represión Política en Chile: una experiencia clínica. Revista Virtual ILAS, n. 4. Intersubjetividad y memoria. Reflexiones sobre los efectos de la entrega del Informe de la Comisión Nacional sobre Prisión Política y Tortura. Disponível em: < http://www.ilas.cl/articulos/ ilas_4/art_8.DOC>. Acesso em: 10 ago. 2008.19p. 
HUYSSEN, A. En busca del futuro perdido. Cultura y memoria en tiempos de globalización. México: FCE, 2002.

LACAPRA, Dominick. Escribir la historia, escribir el trauma. Buenos Aires: Nueva Visión, 2005.

LAUB, Dori. An Event without a Witness: Truth, testimony and Survival, Felman, Shosana y Laub, Dori Testimony. In: ____ Crises of Witnessing in Literature, Psychoanalysis, and History. Nueva York: Routledge, 1992. p. 75-92.

LECHNER, Norbert; GUELL, Pedro. Construcción social de las memorias en la transición chilena. In: JELIN, Elizabeth; KAUFMAN, Susana G. (Comp.). Subjetividad y figuras de la memoria. [s. L.]: Ed. Siglo XXI. Volumen 12: Memorias de la Represión, junio 2006. p. $17-46$.

LIRA, Elizabeth (1991). Psicología de la Amenaza política y del miedo. Disponível em: http: <//www.dinarte.es/salud.../pdfs/Lira\%20E\%20\%20Psicologia\%20de\%20la\%20 Amenaza\%20P>. Acesso em: 10 nov. 2008. 287p.

NICHOLLS, Nancy. Casa de la Memoria. Puntos de Vista, oct. 2007, site web FASIC; $<$ www.fasic.org $>$.

NICHOLLS, Nancy. Las paradojas de la memoria del pasado reciente en Chile: entre el boom y la negación. Puentes, Año 7, n. 22, p.34-39, Comisión Provincial de la Memoria, La Plata, Argentina, 2007.

NICHOLLS, Nancy. Cine, Memoria e Historia: la experiencia del campo de concentración Chacabuco, conferência apresentada na Escola de História UAHC e Goethe Institut, Santiago de Chile, 2007.

NORA, P. Les lieux de mémoire. Paris: Étude, 1997.

RICCEUR, Paul. La mémoire, l'histoire, l'oubli. Paris: Seuil, 2000. 695p.

SALAZAR, Gabriel; PINTO, Julio. Historia contemporánea de Chile. Actores, identidad y movimiento. II. Santiago de Chile: Lom, 1999, 173p.

STERN, Steve J. De la memoria suelta a la memoria emblemática: hacia el recordar y el olvidar como proceso histórico (Chile, 1973-1998). In: GARCÉS, M. et al. Memoria para un nuevo siglo. Chile, miradas a la segunda mitad del sigo XX. Santiago de Chile: Lom Ediciones, 2000. p. 11-33.

TAYLOR, Diana. The Archive and Repertoire. Performing Cultural Memory in the Americas. Durham: Duke University Press, 2003. 326p.

TAYLOR, Diana. Performance and/as History. The Drama Review, 50:1, Spring, New York and the Massachusetts Institute of Technology, 2006. p. 67-85.

TRAVERSO, E. El pasado. Instrucciones de uso. Historia, memoria, política. Barcelona: Marcial Pons, 2007.

WHITE, Hayden. Metahistoria. La imaginación histórica en la Europa del siglo XIX. Buenos Aires: FCE, 1998. 439p.

ZATZMAN, Belarie. Staging History: Aesthetics and the Performance of Memory, en Journal of Aestethetics and Education, v. 39, n. 4, p. 95-103, University of Illinois, Winter 2005. 